\title{
Hydrologic detection and finite element modeling of a slow slip event in the Costa Rica prism toe
}

\author{
Alison L. LaBonte, ${ }^{1,2}$ Kevin M. Brown, ${ }^{1}$ and Yuri Fialko ${ }^{1}$ \\ Received 16 May 2008; revised 11 December 2008; accepted 22 January 2009; published 9 April 2009.
}

[1] We investigate transient fluid flux through the seafloor recorded near the Costa Rica trench during the 2000 Costa Rica Seismogenic Zone Experiment using a 2-D fully coupled poroelastic finite element model. We demonstrate that the observed hydrologic anomalies are consistent with a model of propagating slow slip at the subduction interface between the frontal prism and downgoing plate. There are two sources of volumetric strain that drive fluid flux at the seafloor in response to fault slip at depth: (1) compression and dilation in the vicinity of the tips of a slipping patch and (2) extension and compression due to flexure of the seafloor. The superposition of these two effects results in distinctive spatial and temporal patterns of fluid flow through the seafloor. In a forward modeling approach, time series from shear ruptures with a range of fault length-to-depth ratios in a heterogeneous crust are generated and compared with flow rate observations. Assuming a constant propagation rate and an elliptical profile for the distribution of slip along the decollement, the set of model predictions enables us to infer the probable rupture location, extent, propagation velocity, and duration from a single flow rate time series. The best fit model suggests that the slow slip event initiated within the toe at a depth of less than $4 \mathrm{~km}$ and propagated bilaterally at an average rate of $0.5 \mathrm{~km} \mathrm{~d}^{-1}$. This interpretation implies that stress in the shallow subduction zone is relieved episodically. Furthermore, the Costa Rica data suggest that episodic slow slip events may initiate in the prism toe without being triggered by a seismic event further downdip.

Citation: LaBonte, A. L., K. M. Brown, and Y. Fialko (2009), Hydrologic detection and finite element modeling of a slow slip event in the Costa Rica prism toe, J. Geophys. Res., 114, B00A02, doi:10.1029/2008JB005806.

\section{Introduction}

[2] The subduction interface can generally be divided into zones of stable sliding updip and downdip of a seismogenic zone. During the interseismic phase of the earthquake cycle the seismogenic zone is usually locked but downdip and updip zones may experience steady or episodic creep. Recent land-based geodetic and seismic observations of episodic tremor and slip events downdip of the seismogenic zone [Dragert et al., 2001; Obara, 2002; Rogers and Dragert, 2003; Dragert et al., 2004] reveal the mechanical complexity of the "stable sliding" parts of the subduction fault. From the few offshore hydrologic observations to date, there is evidence that transient deformation also occurs in the stable sliding updip subduction zone plate interface. Accurate characterization of transient events during the interseismic period, in particular these scarcely observed offshore events, is the focus of this study. With each deformation event stress is redistributed to neighboring sections of the plate interface. Knowledge of transients both updip and downdip of the seismogenic zone may help to

\footnotetext{
${ }^{1}$ Scripps Institution of Oceanography, La Jolla, California, USA.

${ }^{2}$ Now at NEPTUNE Canada, University of Victoria, Victoria, British Columbia, Canada.

Copyright 2009 by the American Geophysical Union. 0148-0227/09/2008JB005806\$09.00
}

understand the kinematics and mechanics of the seismogenic zone. Inversions of GPS observations have indicated that the "stick-slip" (velocity weakening) zone is also not converging at the full plate velocity during the interseismic period [Norabuena et al., 2004; Schwartz and DeShon, 2007]. This partial geodetic locking suggests that some portion of strain from plate convergence must be accommodated through aseismic slip during the interseismic period [e.g., Nishimura et al., 2000; Norabuena et al., 2004; Hasegawa et al., 2007; Schwartz and DeShon, 2007]. These uncertainties in the behavior of the different parts of the subduction zone, as well as interactions between the locked and creeping sections of the subduction interface clearly need to be addressed in order to assess earthquake and tsunami hazards [Wang and Hu, 2006; Wang and He, 2008].

[3] In the absence of offshore geodetic measurements to resolve deformation in the shallow subduction zone updip of the seismogenic section, hydrologic observations (e.g., measurements of pore pressure and fluid flow) provide unique means for characterizing and quantifying interseismic deformation. The volumetric strain that results from a deformation event, either seismogenic or aseismic, causes a change in pore pressure. Seafloor borehole observatories monitoring pore pressure in the Nankai prism off Japan recorded two anomalous pressure events coincident with very low frequency earthquakes in the shallow subduction 

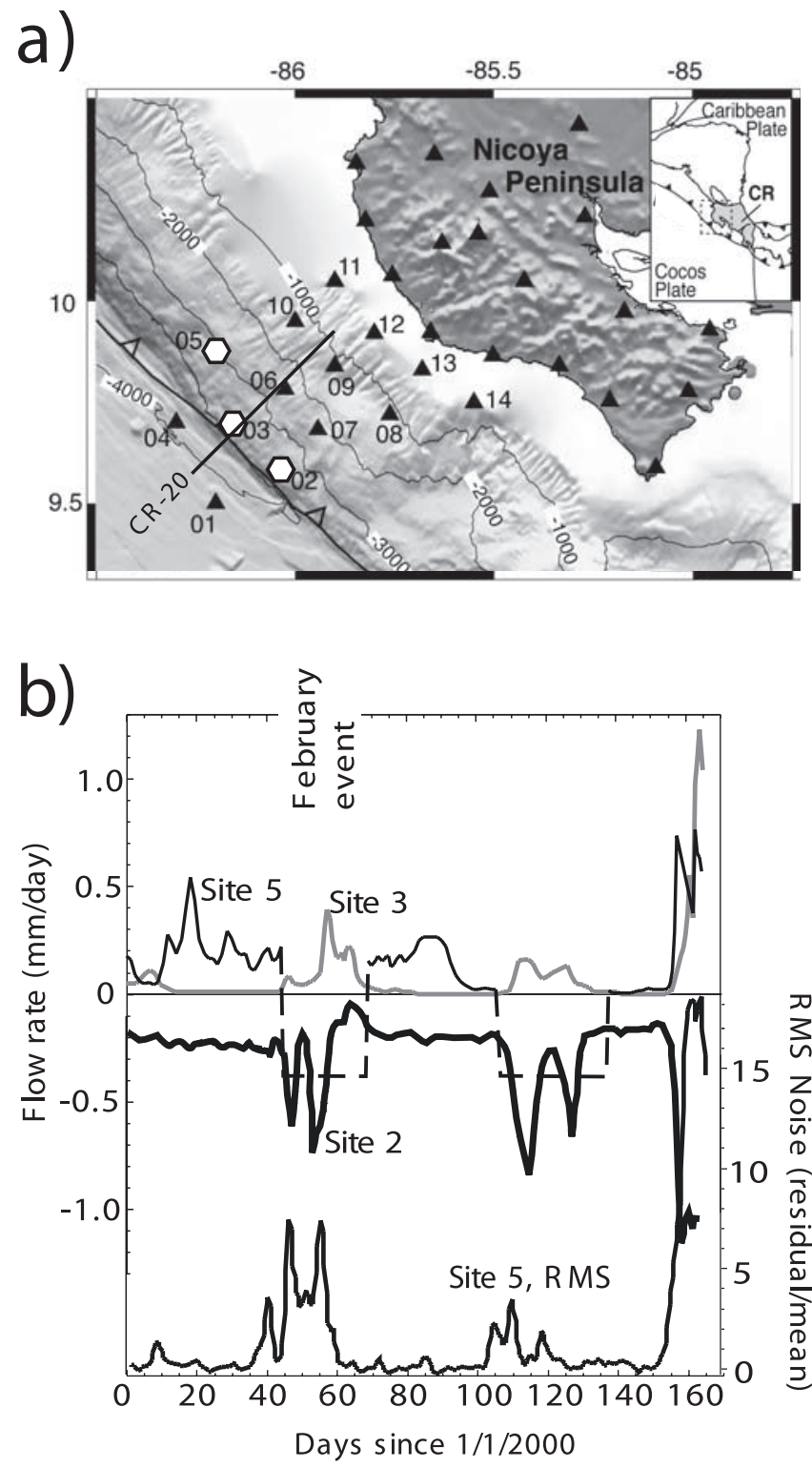

Figure 1. (a) Location of the 14 flowmeters in the Costa Rica (CR) subduction zone during the 2000 CRSEIZE (modified from Brown et al. [2005] with permission from Elsevier) plotted with the trace of seismic line CR-20 [Silver, 2001]. (b) Three instruments on the prism toe (hexagons) recorded time series with three 2.5- to 3.5-weeklong periods of flow rate transience. An instrument malfunction prevented recording of downflow rates at site 5 (dashed line). An ocean bottom seismometer at site 5 recorded high root-mean-square (RMS) noise, a measure for residual vertical accelerations, during the same period (modified from Brown et al. [2005] with permission from Elsevier).

zone off Cape Muroto (2003 event) and the Kii Peninsula (2004 event) [Obara and Ito, 2005; Davis et al., 2006; Ito and Obara, 2006; Davis et al., 2009]. These events, indicative of transient deformation updip of the seismogenic zone, were not preceded or accompanied by any "normal" seismic activity, suggesting a mechanism exists that allows for initiation of shallow slip transience without triggering by a deeper seismic event.

[4] In 2003, borehole formation pressure gauges in Costa Rica also recorded two transient events in the toe of the prism, $\sim 60 \mathrm{~km}$ offshore [Davis and Villinger, 2006]. The latter pressure transient occurred about 3 weeks after GPS instruments at the Nicoya Peninsula detected initiation of a downdip propagating slow slip event [Protti et al., 2004]. Davis and Villinger [2006] suggest the pressure transient may have been a result of a slow slip event that propagated updip to the trench, mirroring the onshore propagation, and imply that the slip was bilaterally propagating. Screaton and $G e$ [2007] modeled a propagating slow slip event to predict pore pressures at various borehole depths above and below the rupture plane and at different cross-strike distances. Their model prediction is consistent with fluid pressure observations from a single site during the Costa Rica 2003 transient event [Davis and Villinger, 2006], but at least one additional measurement at a different cross-strike location above the fault is required to associate the observed signals with a slow slip event, and to determine the direction of propagation.

[5] Pore pressure gradients resulting from deformation also drive fluids up out of and down into the seafloor. During a 180-day experiment off Costa Rica's Nicoya Peninsula in 2000, an anomalous downflow event sequence on the outer rise of the incoming plate and three discrete flow events at the toe of the prism (Figure 1) were observed [Tryon, 2002; Brown et al., 2005]. A grid of 14 Chemical Aqueous Transport (CAT) flowmeters [Tryon et al., 2001], deployed as part of larger ocean bottom seismometer packages [Jacobson et al., 1991], spanned the offshore extent of the subduction wedge, from the coast to beyond the trench, $70 \mathrm{~km}$ offshore (Figure 1a). The event recorded on one of the two outer rise instruments lasted the duration of the deployment and has been interpreted as the result of aseismic extension [Tryon, 2009]. The three flow transients on the subduction wedge were observed simultaneously by instruments located on the frontal prism at sites 2, 3 and 5, spanning an along-strike distance of $30 \mathrm{~km}$. The ocean bottom seismometers recorded no normal seismic activity associated with the flow events. However, a tremor-like noise was recorded suggesting that the anomalous flow rates likely resulted from a deformation event with some accompanying ground motion.

[6] Prior to collecting these data off Costa Rica's Nicoya Peninsula, the instruments were deployed for 3 months off the Osa Peninsula. Although flow rate transience was observed at many sites, flow events were not correlated and seismicity was low [Tryon and Brown, 2000; Tryon, 2002]. Correlated flow transients have only been observed in one other subduction zone study. Four CAT meters deployed for 1 year on seep sites within a small $40 \mathrm{~m}$ diameter area at the Cascadia subduction zone in late 2004 recorded analogous changes in flow rate over a 3-month period [LaBonte, 2007]. The flow transients could simply be correlated to each other due to change in a shared seep source rather than an underlying deformation event. Investigation of data from a broad ocean bottom seismometer network for evidence of ground motion during this time period is therefore prerequisite to any modeling analyses. 


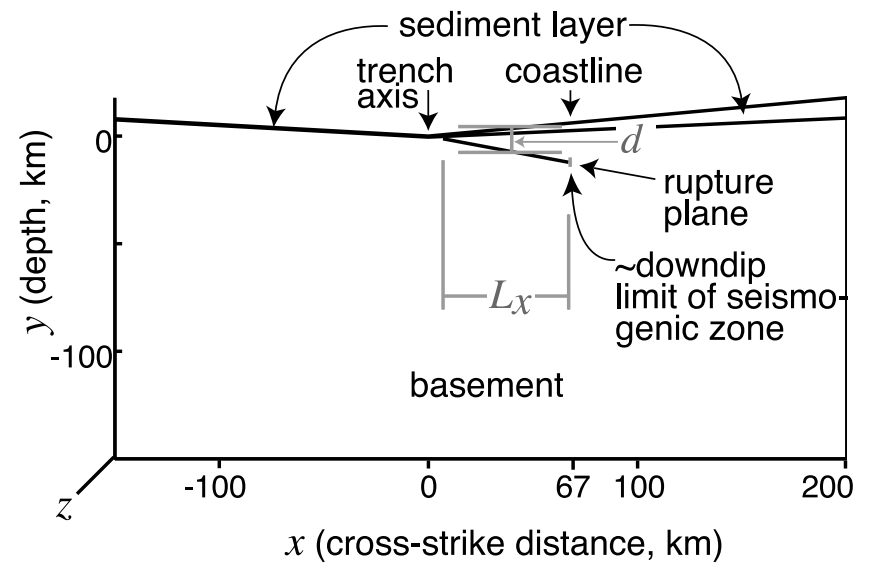

Figure 2. Cross section of the Costa Rica subduction zone layered model geometry. Displacement occurs on the modeled rupture plane, a simplified representation of the steepening decollement. The largest modeled rupture length illustrated here extends from near the trench axis to the downdip limit of the seismogenic zone [Schwartz and DeShon, 2007] and has an average depth, $d$, and horizontal rupture length, $L_{x}$.

[7] In this paper we perform a quantitative investigation of the deformation event that resulted in the February flow event observed on the prism toe off Costa Rica's Nicoya Peninsula (Figure 1). Interpretation of hydrologic or geodetic records typically involves comparing the observations to predictions of theoretical or numerical models [Roeloffs, 1996; Jonsson et al., 2003; Fialko, 2004a; Screaton and Ge, 2007]. In a similar approach, we develop a poroelastic model to simulate numerically the hydrologic response to instantaneous (seismic) and slow (aseismic) slip on a fault, and predict pore pressure and flow rate at the seafloor. We first gain a qualitative understanding of the interaction of physical mechanisms driving fluid flow through the seafloor boundary that renders unique seafloor flux patterns in both space and time; and then demonstrate that a single seafloor observation in the cross-strike direction may be sufficient to identify fault slip and infer its characteristics. In our case study, the poroelastic model predictions are used to quantify a probable set of slow slip parameters (e.g., location, extent, propagation velocity and duration) that best reproduces the flow rate time series recorded at the toe of the Costa Rica fore-arc prism.

\section{The Poroelastic Model}

[8] To predict seafloor flow rates in response to instantaneous and slow slip deformation we used a commercial finite element software package Abaqus. The use of a finite element model (FEM) allowed us to perform fully coupled poroelastic simulations using realistic fault and seafloor geometries and spatially variable material properties. The subduction zone and the plate interface are assumed to be infinite in the along-strike direction, $z$ (Figure 2), and the governing equations with plane strain conditions were used to relate strain and fluid mass content per unit volume to stress and pore pressure. These equations require a set of five independent poroelastic constants: two drained framework elastic moduli (the Poisson's ratio, $v$, and the frame bulk modulus, $K$ ), the fluid bulk modulus, $K_{f}$, the solid grain bulk modulus, $K_{s}$, and the porosity, $n$. The force equilibrium equations and a pressure diffusion equation derived from the laws of Darcy and fluid-mass conservation complete the set of governing equations [Biot, 1941; Rice and Cleary, 1976; Roeloffs, 1996; Wang, 2000]. The FEM simulations produce displacement and pore pressure fields from which flow rate through the seafloor boundary is calculated using Darcy's law:

$$
q=-\frac{k}{\mu} \frac{\partial p}{\partial y}
$$

where $k$ is the permeability of the porous medium, $\mu$ is the viscosity of the fluid, and $\partial p / \partial y$ is the vertical pressure gradient driving the fluid flow (the background hydrostatic component has been removed).

\subsection{Model Geometry, Material Properties, and Boundary Conditions}

[9] The model geometry of the Costa Rica subduction zone was based on seafloor bathymetry, the thickness of the slope sediments, and depth and dip of the decollement as interpreted from seismic sections of the margin [Shipley et al., 1992; Christeson et al., 1999; Silver, 2001]. The seafloor surface dips $5^{\circ}$ toward the trench landward of the trench, and $3^{\circ}$ seaward of the trench (Figure 2). The walls and bottom of the computational domain were placed $\sim 150 \mathrm{~km}$ from the fault surface to minimize any edge effects. A $0.5-\mathrm{km}$-thick sediment layer overlies the oceanic and fore-arc basement layer and linearly thickens landward to over $2 \mathrm{~km}$ at the continental margin.

[10] The poroelastic constants used in our simulations for the basement rock and the sediment apron are summarized in Table 1. The values for sediment and basement layers are mainly derived from in situ borehole measurements of formation pressure response to tidal loading and represent formation properties over a scale of tens of meters. We assigned both the subducting Cocos basement and the Nicoya ophiolite complex that constitutes the prism the same "basement" material properties because surface flow rates are primarily dependent on properties of the much less permeable overlying sediment layer. A sensitivity analysis confirmed that surface flow rates are largely insensitive to differences in the basement material properties. Instead, the amplitude of flow rate through the seafloor is only sensitive to the material properties of the upper several meters of sediment that are able to drain over the duration of the slip event. Since the very near surface $(<1 \mathrm{~m}$ depth) sediment permeability and elastic moduli are not well constrained, the primary intent of this study is to explore the cause for the unique temporal pattern in flow rate which is insensitive to the surface material properties.

[11] The surface along which the presumed slip events occur dips $10^{\circ}$ landward, an average of the steepening dip angle of the decollement between the toe and the coastline. Use of a constant dip angle to represent the fault plane ensures self-similarity of model predictions at any spatial scale so the model results can be scaled to represent the geometry of a specific site. The fault is modeled as a highly sheared elastic band, i.e., displacement of the hanging wall relative to the footwall is accommodated within a $10 \mathrm{~m}$ 
Table 1. Poroelastic Material Parameters for Costa Rica ${ }^{\mathrm{a}}$

\begin{tabular}{|c|c|c|c|}
\hline Material Properties & Parameter & Sediment & Basement \\
\hline Poisson's ratio & $v$ & 0.10 (WD; DV) & $0.30(\mathrm{DV})$ \\
\hline Frame bulk modulus $(\mathrm{Pa})$ & $K$ & $2.5 \times 10^{8}(\mathrm{DV})$ & $7.7 \times 10^{9}(\mathrm{DV})$ \\
\hline Grain bulk modulus $(\mathrm{Pa})$ & $K_{s}$ & $5.0 \times 10^{10}(\mathrm{DV})$ & $5.0 \times 10^{10}(\mathrm{DV})$ \\
\hline Fluid bulk modulus $(\mathrm{Pa})$ & $K_{f}$ & $2.4 \times 10^{9}(\mathrm{DV})$ & $2.4 \times 10^{9}(\mathrm{DV})$ \\
\hline Permeability $\left(\mathrm{m}^{2}\right)$ & $k$ & $10^{-15}(\mathrm{BD}, \mathrm{S}, \mathrm{DV})$ & $10^{-13}(\mathrm{D}, \mathrm{DV})$ \\
\hline Porosity & $n$ & $0.6(\mathrm{~K}, \mathrm{~B}, \mathrm{DV})$ & $0.1(\mathrm{DV})$ \\
\hline Shear modulus $(\mathrm{Pa})$ & $G$ & $2.7 \times 10^{8}$ & $3.6 \times 10^{9}$ \\
\hline 1-D loading efficiency & $\gamma$ & $0.86(\mathrm{DV})$ & $0.58(\mathrm{DV})$ \\
\hline 1-D hydraulic diffusivity $\left(\mathrm{m}^{2} \mathrm{~s}^{-1}\right)$ & $c$ & $5.2 \times 10^{-4}$ & 0.85 \\
\hline 1-D storage compressibility $\left(\mathrm{Pa}^{-1}\right)$ & $S$ & $1.9 \times 10^{-9}$ & $1.1 \times 10^{-10}$ \\
\hline Dynamic viscosity $(\mathrm{Pa} \mathrm{s})$ & $\mu$ & $10^{-3}$ & $10^{-3}$ \\
\hline
\end{tabular}

thick fault zone. This representation of fault slip was chosen to ensure mesh continuity and allow fluid flow across the slip interface. A set of FEM geometries was generated in order to characterize surface fluid velocities for a range of faults with different fault length-to-depth ratios, $L_{x} / d$, where $L_{x}$ is the horizontal component of fault length and $d$ is the average depth of the fault beneath the seafloor (Figure 2).

[12] The modeled fault has the same permeability as the host material. Analytical models of edge dislocations on permeable $(p=0)$ and impermeable $(\partial p / \partial y=0)$ dislocation planes demonstrate that the pore pressure fields for these two end-member cases are essentially identical at two diffusion lengths above the fault [Rudnicki, 1986]. Diffusion length, $2 \sqrt{c t}$, is the characteristic length the pressure wavefront will travel in a specified time, $t$, through a media with hydraulic diffusivity, $c$ :

$$
c=\frac{k}{\mu S},
$$

where $S$ is the one-dimensional storage compressibility. Therefore, the permeability of the fault in our models is insignificant as long as the depth of the fault is greater than $4 \sqrt{c t}$. This equates to a minimum fault depth of $135 \mathrm{~m}$ in sediment for the February Costa Rica event with an estimated maximum duration of 3.5 weeks (Figure 1b).

[13] The pore pressure (relative to hydrostatic) is initially set to zero throughout the computational domain. The walls and bottom of the finite element mesh are assumed to have zero displacements and be impermeable to flow. The top of the mesh (representing the seafloor) is a stress-free boundary with a null pore pressure boundary condition $(p=0)$, and is permeable to flow.

\subsection{FEM Analysis}

[14] The fully coupled poroelastic FEM simulations consist of a deformation step in which displacement is applied and the resulting anomalous fluid pressure begins to drive fluid diffusion, and a relaxation step in which pore fluids continue to diffuse as the pressure field equilibrates. We use an adaptive time stepping scheme that ensures numerical convergence for both the deformation and fluid flow parts of the problem. Displacement, pore pressure, and fluid velocity fields are calculated at each iteration in time. Of primary relevance in this study is the vertical component of fluid velocity at the seafloor through time and space.

[15] In instantaneous slip simulations, the initial deformation step is $10^{-6} \mathrm{~s}$ in duration. Flow rate predictions are made in the relaxation step after a sufficient time in order to exclude any dynamic processes and avoid numerical errors. Numerical oscillations can occur at early times at the seafloor boundary because the imposed null pore pressure boundary condition creates an infinitely steep pore pressure gradient immediately after deformation initiates. By using a seafloor surface element size of $0.01 \mathrm{~m}$ and gradually increasing the element size away from the surface, flow rates can be resolved at very early times.

[16] In propagating slow slip simulations the displacement boundary condition, which varies in time as the length of the slipping patch increases, is linearly applied over the duration of the deformation step. Surface flow rate is calculated at each of 100 evenly spaced iterations resulting in a flow rate time series for each surface element. This is necessary in order to resolve variations in surface flow rate as a result of temporally and spatially variable fault slip. The relaxation step is several years long and iterations are more closely spaced at the beginning of the step when pore pressures are changing more rapidly.

\subsection{Methods}

[17] The boundary condition applied in the deformation step is the along-fault displacement distribution, $D$, that mimics the constant stress drop on a fault in an unbounded homogeneous elastic medium [Lawn, 1993; Fialko, 2004b, 2007],

$$
D=\frac{b \sqrt{\left(\frac{L_{x}}{2}\right)^{2}-\bar{x}^{2}}}{\frac{L_{x}}{2}},
$$

for

$$
|\bar{x}| \leq \frac{L_{x}}{2}
$$

where $b$ is the maximum displacement, taken to be positive for thrust motion, and $\bar{x}$ is the coordinate of the middle of 


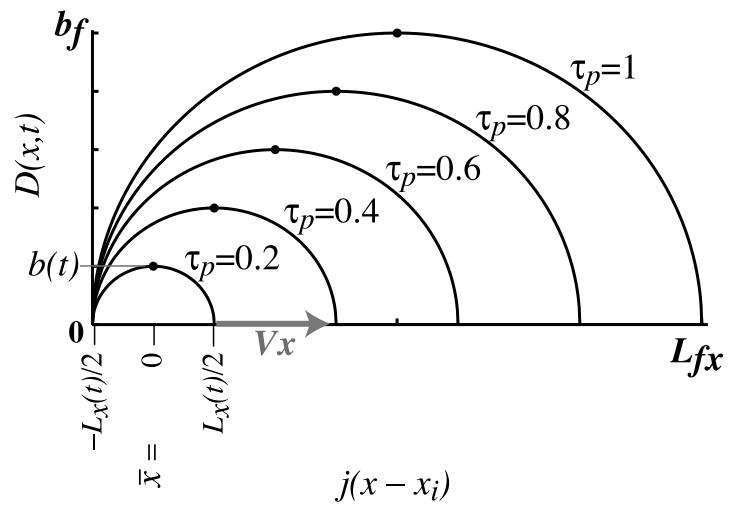

Figure 3. Schematic of displacement distribution, $D(x, t)$, for the duration (dimensionless propagation time of $0<\tau_{p}<$ $1)$ of a slow slip event propagating downdip $(j=1)$ or updip $(j=-1)$ at velocity $V_{x}$. The term $b(t)$ is the maximum slip displacement over the horizontal rupture length, $L_{x}(t)$. The parameters $b_{f}$ and $L_{f x}$ are the final slip displacement and rupture length values, respectively, once propagation has ceased $\left(\tau_{p}=1\right)$. The $x$ axis is shifted so rupture initiation location, $x_{i}$, plots at the origin. The $\bar{x}$ coordinate labels, indicating position relative to the center of the slipped patch, are shown for $\tau_{p}=0.2$.

the slipping patch. Given that the origin $x=0$ is assumed at the trench axis (Figure 2), the following relationship holds:

For instantaneous slip

For propagating slip

For downdip propagation

For updip propagation

$$
\begin{aligned}
\bar{x} & =x-x_{u}-\frac{L_{x}}{2}, \\
\bar{x} & =j\left(x-x_{i}\right)-\frac{L_{x}}{2}, \\
j & =1, \\
j & =-1,
\end{aligned}
$$

where $x_{u}$ is the updip limit of the slipping patch in the instantaneous slip case and $x_{i}$ is the slip nucleation site in the propagating slip cases (Figure 3 ). In the presence of a stress-free seafloor boundary or heterogeneities in the ocean crust [e.g., Masterlark, 2003] the stress drop corresponding to slip distribution (3) is nonconstant. However, the resultant differences in the predicted flow rate patterns at the seafloor are of second order. Lacking constraints on the actual stress drop or slip distribution, we use equation (3) in all simulations.

[18] For slow slip simulations, the horizontal length of the rupture, $L$, and the maximum slip, $b$, vary as a function of time (Figure 3) for dimensionless propagation time $\tau_{p}<1$, i.e., times, $t$, less than the duration of the slow slip event, $t_{f}$ :

$$
\begin{gathered}
L_{x}(t)=V_{x} t, \\
b(t)=b_{f} \tau_{p}, \\
\tau_{p}=\frac{t}{t_{f}}=\frac{V_{x} t}{L_{f x}},
\end{gathered}
$$

where $V_{x}$ is the horizontal component of the velocity of the propagating rupture tip; $b_{f}$ is the final slip magnitude; and
$L_{f x}$ is the horizontal component of the rupture length at the termination of the slow slip propagation, $\tau_{p}=1$.

[19] Simulations were performed for four instantaneous slip and four slow slip scenarios with a range of fault lengthto-depth ratios, $0.5>L_{x} / d>6$ and $3>L_{f x} / d>6$, respectively. Depth, $d$, in the slow slip models is the average depth of the entire fault length at the termination of the event. The fault in all model geometries was centered at a horizontal distance of $37 \mathrm{~km}$ from the toe, which corresponds to an average depth, $d$, of $10 \mathrm{~km}$. The maximum rupture length (cross-strike) of $60 \mathrm{~km}$ was chosen to be consistent with the downdip limit of seismogenic rupture (Figure 2).

\section{Results}

[20] Volumetric strain from flexure of the free boundary surface and compression and dilation at the tips of a buried shear rupture cause distinct spatial and temporal variations of pore pressure and flow rate at the surface. We first present the results from the instantaneous slip FEM simulations and illustrate how the spatial variation in seafloor flux is highly sensitive to the rupture location and extent. Simulated time series from propagating slow slip ruptures are then shown to be highly sensitive to the velocity and duration of propagation as well as location and extent. In our case study, we find the propagating slow slip model parameters that best reproduce the flow rate records observed at two different along-strike locations near the Costa Rica trench axis.

\subsection{Instantaneous Slip Model Predictions}

[21] Figure 4 shows model predictions of the cross-strike variation in flow rate for faults with different $L_{x} / d$, in layered models and a homogeneous sediment model. Postseismic flow rate predictions were made at $t=10 \mathrm{~s}$. The decay in surface fluid flux following a sudden change in pore pressure is analogous to the decay in heat flux through the surface of a half-space following an instantaneous change in temperature throughout the half-space [Carslaw and Jaeger, 1959; Turcotte and Schubert, 2002]:

$$
q \propto \frac{1}{\sqrt{c t}} .
$$

This relationship holds for times prior to the arrival of the pressure source originating at depth (e.g., at the rupture tip) to the model surface, or the early postseismic period. Therefore, predictions made at a single time within this period (e.g., $t=10 \mathrm{~s})$ are representative of the cross-strike flow rate variation throughout the early postseismic period.

[22] In addition to time, vertical flow rates, $q$, can be nondimensionalized for slip magnitude, fault depth, and surface "sediment" layer material parameters using natural scales to yield the dimensionless flow rate, $\theta$ :

$$
\theta=q \frac{\mu d \sqrt{c t}}{k \gamma G b}
$$

Loading efficiency, $\gamma$, and shear modulus, $G$, are material parameters (Table 1) relate the change in stress in the poroelastic 


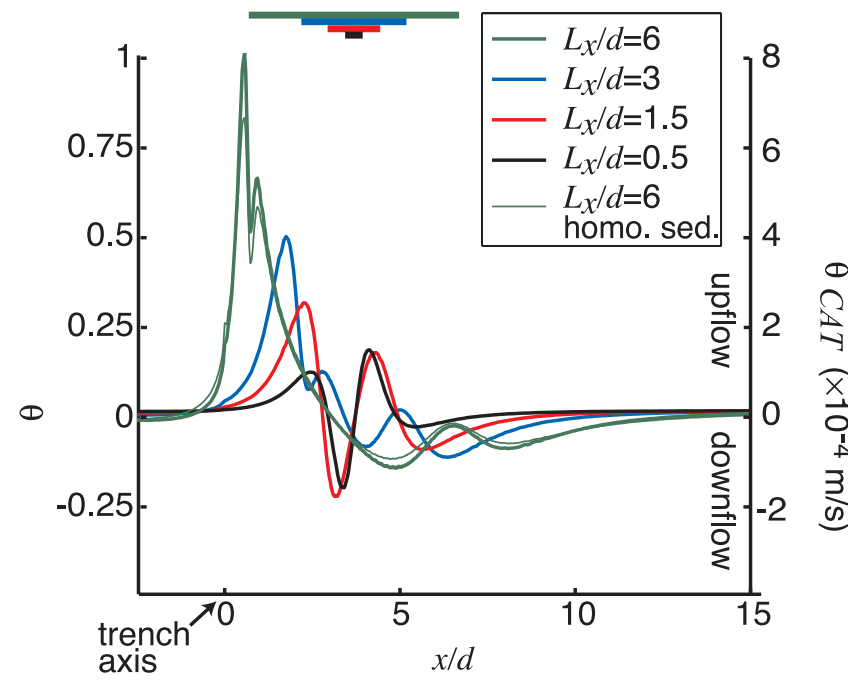

Figure 4. Instantaneous slip FEM predictions for layered (basement and sediment) and homogeneous sediment (thin green line) simulations. Colored bars indicate rupture extent for each fault $L_{x} / d$, where $L_{x}$ is horizontal fault length and $d$ is average depth to the fault. Dimensionless flow rate, $\theta$, is plotted on the primary $y$ axis. The parameter $\theta_{C A T}$, plotted on the secondary $y$ axis, is an average the first $16 \mathrm{~h}$ of the postseismic flow rate through Costa Rica sediment (Table 1).

material to strain and pore pressure [Rice and Cleary, 1976; Rudnicki, 1987; Wang, 2000]. For example, a greater loading efficiency means that pressure from loading the porous matrix is transferred more effectively to interstitial pore waters, which drives the pore pressure up higher and results in a greater flow rate than is generated through loading a matrix with smaller loading efficiency. The minimal sensitivity to differences in basement layer material properties is evidenced in the comparison of the layered model to an extreme, homogeneous sediment model (Figure $4, L_{x} / d=6$ ).

[23] The coseismic pore pressure field and seafloor flow rates are a result of local volumetric strain from (1) lobes of compression and dilation that result from fault slip and (2) flexure of the stress-free seafloor boundary. These two contributors to volumetric strain result in a unique crossstrike flow rate pattern for each fault length-to-depth ratio $L_{x} / d$ (Figure 4 ) in the modeled Costa Rica geometry. If displacement at the seafloor were prohibited, the flow rate pattern at the seafloor in response to slip on a buried fault would be a single peak in upflow velocity above the compressional lobe (labeled CL in the pore pressure field, $p(x, y)$, shown in Figure 5), and a peak in downflow velocity above the dilational lobe (DL). In the near field (e.g., $L_{x} / d=$ 6 in Figure 5b), compressional and dilational lobes are directly above the updip and downdip rupture tips, respectively, whereas in the far field (e.g., $L_{x} / d=0.5$ in Figure 5a), the respective lobes are further apart and outward from the rupture tips.

[24] Because the seafloor is a deformable stress-free boundary, a more complicated flow rate pattern results from the additional contribution of seafloor flexure to volumetric strain. The effect of seafloor flexure is illustrated in Figure 5 with a vertically exaggerated deformed seafloor along with vectors that represent vertical flow rate through the seafloor. In both near-field and far-field cases, extensional flexure
(EF) drives downward fluid flow above the updip rupture tip and compressional flexure (CF) drives upward fluid flow above the downdip rupture tip. For "near-field" thrust faults $\left(L_{x} / d \geq 3\right)$, extensional flexure and the compressional lobe directly line up above the updip rupture tip. The superposition of these two opposing effects results in a "dimpled" or "double" upflow peak above the updip rupture tip. A broader, but similar, double downflow peak occurs where compressional flexure and the dilatational lobe line up above the downdip rupture tip (Figure 5b). For "far-field" ruptures $\left(L_{x} / d<3\right)$, the compressional and dilatational lobes are located sufficiently outward from the rupture tips. Therefore, only a single peak in flow rate, with a direction controlled by the flexure effect, occurs over the rupture tips (Figure 5a).

\subsection{Transient Slow Slip Model Predictions}

[25] Figure 6 shows snapshots in time of the cross-strike variation of vertical flow rates through the seafloor in
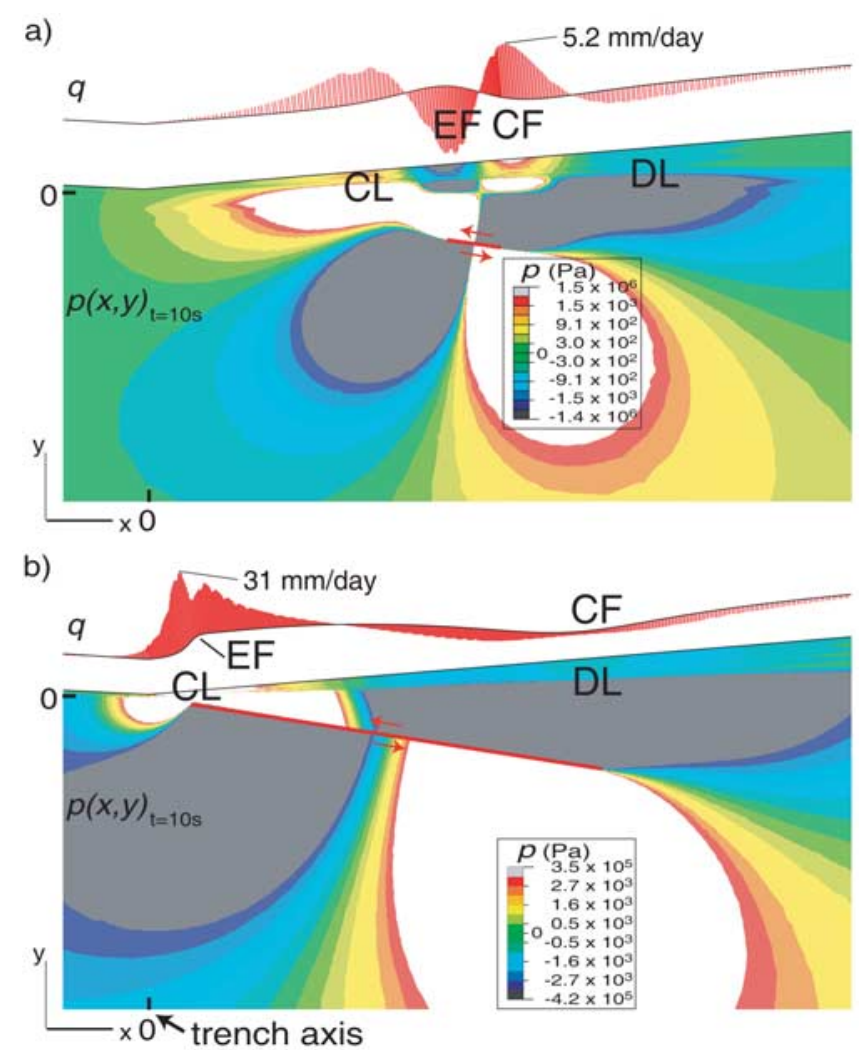

Figure 5. Response to an instantaneous slip thrust event centered at $37 \mathrm{~km}$ from the trench axis and $10 \mathrm{~km}$ depth with displacement $b=1.1 \mathrm{~m}$ in Costa Rica layered material geometry (Figure 2 and Table 1) evaluated at $t=10 \mathrm{~s}$. Extensional and compressional flexure (EF and $\mathrm{CF}$ ) of the seafloor (plotted with vertical exaggeration) effect the vertical flow rate, $q$ (vertical red vectors), through the seafloor. Lobes of compression and dilation (CL and DL) extending out from the rupture as seen in the pore pressure field, $p(x, y)$, also effect $q$. Superposition of these two effects result in characteristic differences of cross-strike flow rate patterns for (a) far-field $\left(L_{x} / d=0.5\right)$ and (b) near-field $\left(L_{x} / d=6\right)$ ruptures. 
downdip propagating

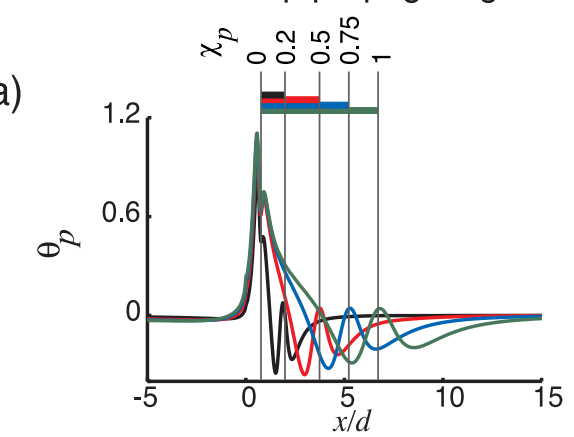

c)

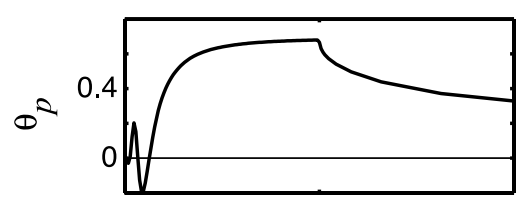

e)

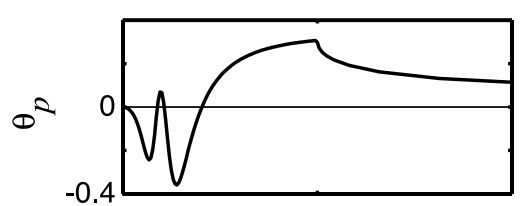

g)

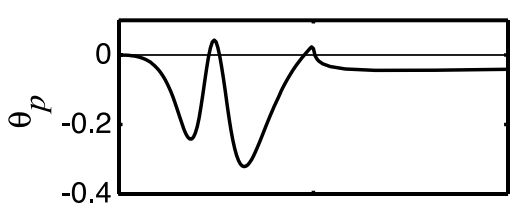

i)

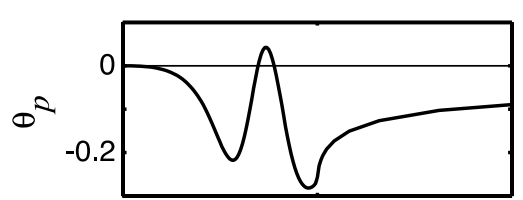

k)

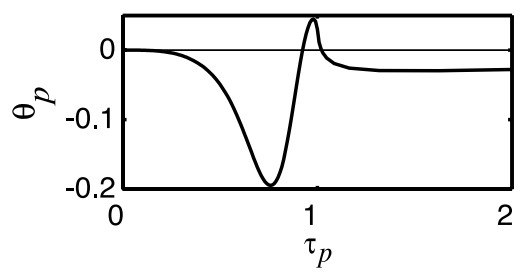

updip propagating

b)

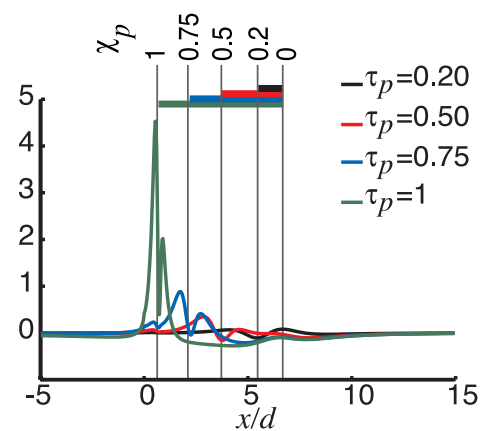

d)

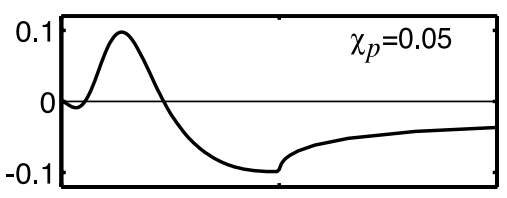

f)

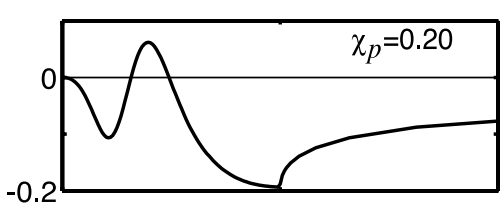

h)

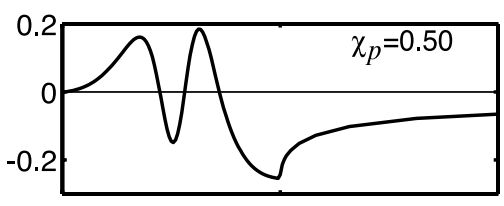

j)

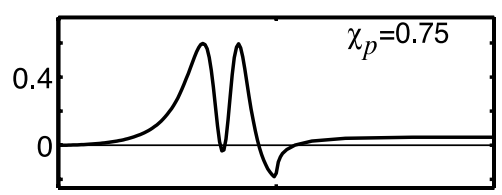

l)

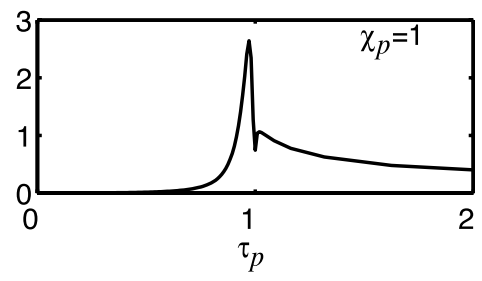

Figure 6. ( $\mathrm{a}$ and $\mathrm{b}$ ) Snapshots of dimensionless flow rate predictions, $\theta_{p}$, for downdip and updip propagating ruptures, $L_{f x} / d=6$, through the layered model geometry at four dimensionless propagation times, $\tau_{p}$. Colored bars represent extent of rupture at each $\tau_{p}$ value; propagation terminates at $\tau_{p}=1$. (c-l) Time series predictions, $\theta_{p}$, for dimensionless observation locations, $\chi_{p}$.

response to updip and downdip propagating ruptures in the layered model. Flow rate predictions for $\tau_{p}<1$ are plotted as a modified dimensionless flow rate, $\theta_{p}$ :

$$
\theta_{p}=q \frac{\mu d \sqrt{c L_{f x} / V_{x}}}{k \gamma G b_{f}} .
$$

Unlike the instantaneous slip dimensionless flow rate, $\theta, \theta_{p}$ depends on time, but is independent of the propagation speed $V_{x}$. This is achieved by replacing $t$ in equation (10) with the duration of the slow slip event, $t_{f}$, or $L_{f_{x}} / V_{x}$. The greater the diffusivity is in relation to the propagation speed, the more the strain-induced pore pressure gradient at the seafloor is reduced by drainage.

[26] Roeloffs and Rudnicki [1985] derived the analytical solution for a steadily propagating tip of a semi-infinite fault. The variation in pore pressure through time as a horizontally propagating tip passes beneath a stationary observer was demonstrated to be akin to the variation in pore pressure seen by an observer sliding along a horizontal plane above the fault tip at a snapshot in time. We use this 
a)

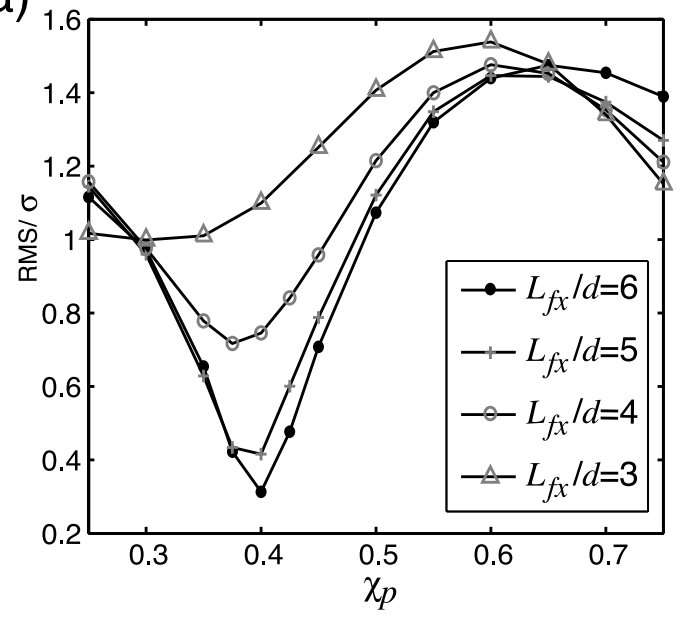

b)

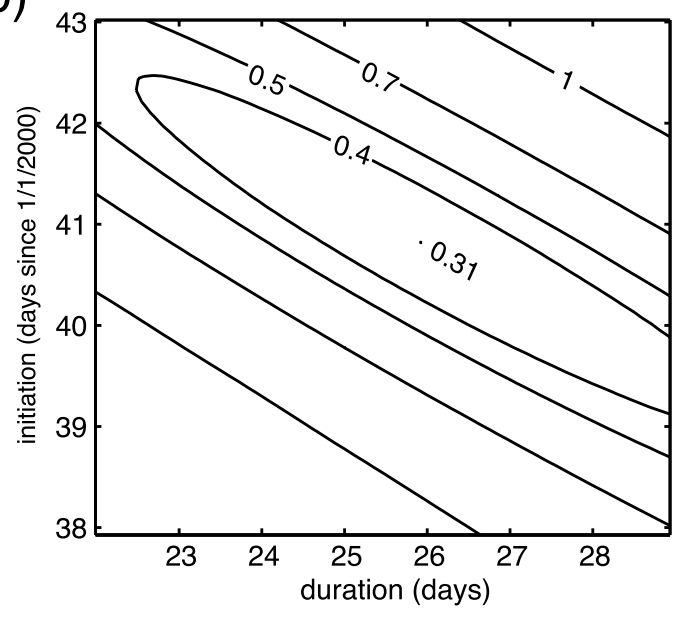

Figure 7. Misfit calculations between predicted and site 2 February time series (long-term background flow rate removed) are measured as the root-mean-square of residuals normalized by the standard deviation of the observation record over a 35-day window beginning on 12 February 2000. (a) Misfit calculations for a matrix of fault $L_{f_{x}} / d$ ratios and dimensionless observation locations, $\chi_{p}$. Slow slip initiation date and duration were fixed at 10 February 2000 and 25.5 days, respectively, but slip amplitude, $b$, is adjusted individually for minimum misfit. (b) Contour plot of misfit, RMS $\sigma$, as a function of duration and initiation with fixed best fit values $L_{f x} / d=6$ and $\chi_{p}=0.4 \mathrm{~m}$.

same convolution concept for a finite rupture to illustrate that a time series will depend on the observation location, $x_{o b s}$, with respect to the location of initiation, $x_{i}$, and termination, $x_{t}$, of the propagating rupture, in particular, on the dimensionless observation location, $\chi_{p}$ :

$$
\chi_{p}=\frac{x_{o b s}-x_{i}}{x_{t}-x_{i}} .
$$

[27] The time series recorded at an observation point located anywhere above the final fault length $\left(0<\chi_{p}<1\right)$ is similar to the variation in flow rate recorded by an observer that moves along the seafloor from a finite distance before $x_{t}$, passes over the rupture tip, and stops over the fault the same distance before $x_{i}$. As the observer never passes over the slip initiation location, the time series is primarily the signature of extensional flexure and the compressional lobe for an updip propagating slip, and compressional flexure and the dilational lobe for a downdip propagating slip. Hence, like the spatial plots (Figures $6 \mathrm{a}$ and $6 \mathrm{~b}$ ), time series plots (Figures $6 c-61$ ) display the characteristic double peak (or a fraction of the double peak for $\chi_{p}$ values close to 0 and 1): double downflow peaks for downdip propagating ruptures and double upflow peaks for updip propagating ruptures. Just like instantaneous slip predictions are dependent on $L_{x} / d$ (Figure 4), snapshots in time during the slow slip simulation (Figures $6 \mathrm{a}$ and $6 \mathrm{~b}$ ) are dependent on the fault $L_{f x} / d$. Modeled slow slip time series are therefore sensitive to both the observation location $\chi_{p}$, and the fault geometry $L_{f x} / d$.

\subsection{Constraining Location and Timing of Costa Rica Event}

[28] In the following case study, we constrain rupture parameters for a suspected slow slip event that occurred in February 2000 on the Costa Rica prism toe (Figure 1b).
During this period, three CAT meters spanning a $30-\mathrm{km}$ along-strike distance simultaneously recorded anomalous flow rates. We assume that the rupture occurred on the modeled decollement. Since our numerical models correspond to 2-D plane strain conditions, we independently quantify characteristics of the propagating slow slip rupture at along-strike observation sites 2 and 3 (15 km apart). This allows us to investigate possible along-strike variations in the rupture process. The incomplete record due to instrument malfunction at site 5 prevented characterization of the rupture at this third along-strike location.

[29] The flow rate time series observed at site 2 and the model prediction for downdip propagating slow slip at a dimensionless along-fault observation location $\chi_{p}=0.5$ (Figure $6 \mathrm{~g}$ ) share the same characteristic double peak in downflow. On the basis of this similarity, predictions of flow rate time series for dimensionless along-fault observation locations ranging from $0.25 \leq \chi_{p} \leq 0.75$ were generated for downdip propagating slip with $L_{f x} / d$ of 6,5 , 4, and 3. A first-order approximation of propagation duration and initiation was used to scale the timing of predictions. The misfit, estimated as the normalized root-meansquare of the residuals, was calculated between these model predictions and the site 2 record with background flow rate removed (Figure 7a). The amplitude of each flow rate prediction was adjusted to minimize the misfit value for each model-to-observation comparison.

[30] A minimum misfit is obtained for a downdip propagating rupture with $\chi_{p}=0.4$ and $L_{f x} / d=6$ (Figure 7a). In the model geometry, fault depth in terms of distance from the trench axis, $x$, is $0.27 x$. Knowing that the average depth of the fault, $d$, is $L_{f x} / 6$ :

$$
d=0.27\left(\frac{x_{i}+x_{t}}{2}\right)=\frac{L_{f x}}{6},
$$




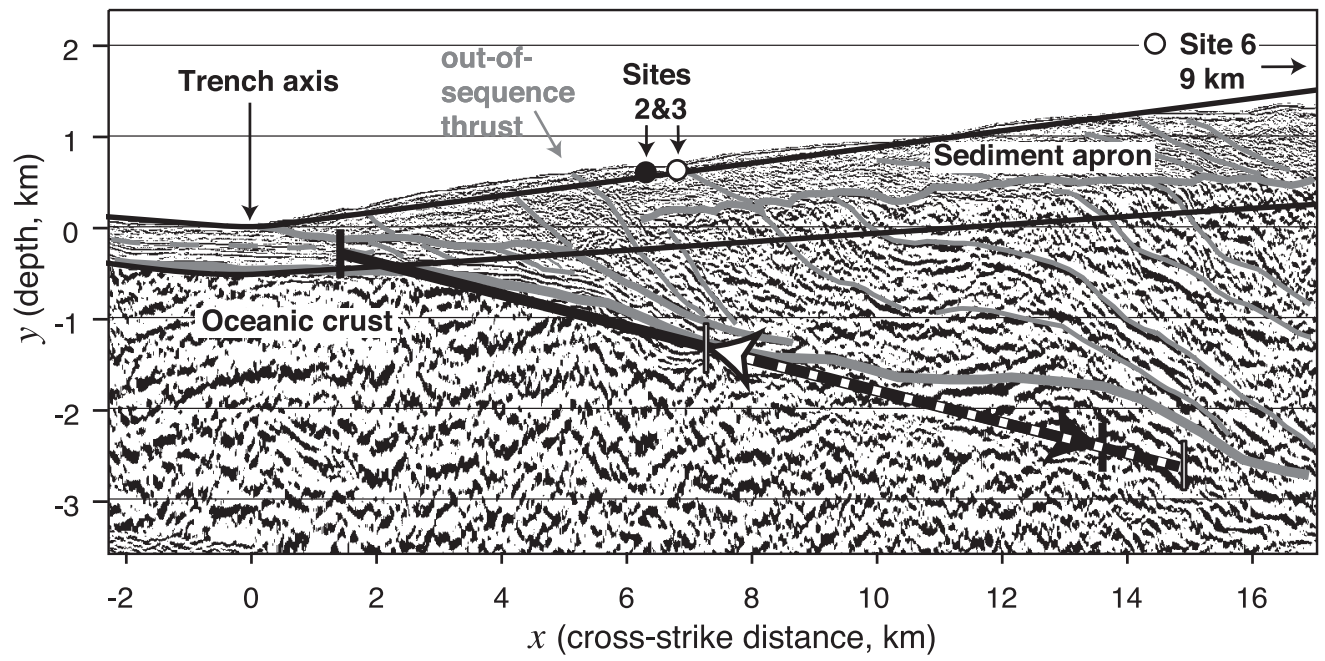

Figure 8. Flowmeter site locations projected onto the same along-strike cross section as seismic line CR-20 (modified from Silver [2001]; gray lines are Silver's inferred fault locations). The February time series at site 2 is reproduced with a downdip propagating rupture (best fit model indicated by solid black arrow). The time series recorded at site $3,15 \mathrm{~km}$ along strike to the northwest, is modeled with an updip propagating rupture on the decollement (dashed line and outlined arrow).

we find the relationship of $x_{i}$ to $L_{f x}$ through substitution of $x_{t}$ (for downdip propagation) and reduction:

$$
\begin{aligned}
x_{t} & =x_{i}+L_{f x}, \\
x_{i} & =\frac{1}{0.27} \frac{L_{f x}}{6}-\frac{L_{f x}}{2}=0.12 L_{f x} .
\end{aligned}
$$

We can now solve for horizontal fault length, $L_{f x}$, and initiation location, $x_{i}$, knowing that site 2 , located $6.3 \mathrm{~km}$ landward from the trench, corresponds to a $\chi_{p}$ of 0.40 :

$$
\begin{aligned}
& \chi_{p}=\frac{6.3 \mathrm{~km}-x_{i}}{L_{f x}}=0.40, \\
& 0.40 L_{f x}+0.12 L_{f x}=6.3 \mathrm{~km}, \\
& L_{f x}=12.2 \mathrm{~km} ; \quad x_{i}=1.4 \mathrm{~km}
\end{aligned}
$$

The inferred rupture initiated $1.4 \mathrm{~km}$ landward from the trench axis and propagated to $13.6 \mathrm{~km}$ landward of the trench (Figure 8). To further optimize the model, the initiation time and duration of the rupture that produce the minimum misfit are calculated (Figure $7 \mathrm{~b}$ ). The resulting scaled best fit model is plotted with the observed time series in Figure 9. Given a 12.2-km cross-strike fault length and a 26-day duration, the inferred horizontal component of propagation velocity is $0.47 \mathrm{~km} \mathrm{~d}^{-1}$.

[31] The anomalous flow rate event at site 3 concurrent with the February site 2 event (Figure 1b) is reproduced (Figure 10a) with an updip propagating rupture along the modeled decollement (Figure 8). Two days after the event initiated at site 2, slow slip rupture initiated landward of site 3 at $x_{i}=15 \mathrm{~km}$, propagated updip at $0.42 \mathrm{~km} \mathrm{~d}^{-1}$, and terminated 18 days later at $x_{t}=7.5 \mathrm{~km}$, not quite passing beneath the site 3 flowmeter at $x_{o b s}=6.8 \mathrm{~km}\left(\chi_{p}=1.1\right)$. Site 6 , located $11 \mathrm{~km}$ landward of the inferred downdip limit of rupture beneath site 3 (Figures 1a and 8), shows little deviation from background flow rate at the time of the slow slip event (Figure 10b). This observation and a similar nonevent at site 7 (landward of site 2) are consistent with predicted flow rates at sites distant from the inferred shallow slow slip rupture.

\subsection{Constraining Slip Magnitude of Costa Rica Event}

[32] Predictions from the instantaneous slip model (Figure 4), where there is practically no pore pressure loss due

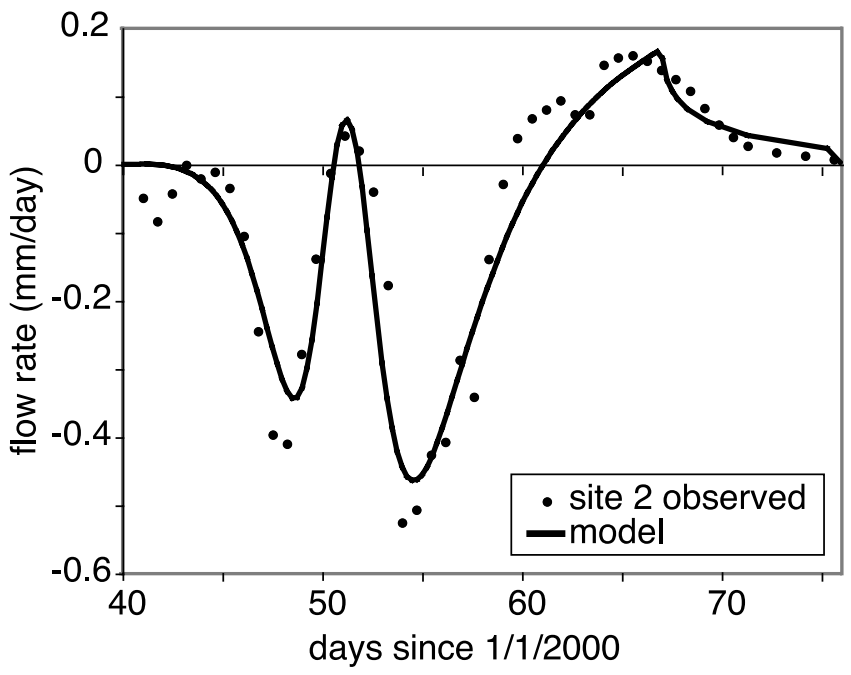

Figure 9. Best fit downdip propagating slow slip prediction for site 2 February time series (background flow rate removed). Prediction assumes Costa Rica sediment material parameters (Table 1). Optimal parameters used to scale best fit model are $L_{f x}=12.2 \mathrm{~km}, d=2.1 \mathrm{~km}, V_{x}=0.47 \mathrm{~km} \mathrm{~d}^{-1}$, and $b_{f}=4.8 \mathrm{~m}$. 
to drainage during slip, provide an upper bound on the downflow rates that can be generated from a rupture with average depth, $d$, and a slip magnitude, $b$. We can then constrain the minimum slip required to produce the peak downflow rate observed during the February transient. The Costa Rica sediment properties (Table 1) and a 16-h smoothing window to mimic the CAT meter sampling method $\left(t_{\mathrm{CAT}}=57,600 \mathrm{~s}\right)$ are applied to obtain a prediction, $q_{\text {CAT, }}$ of the flow rate through sediment observed by the CAT meter following instantaneous slip at a depth, $d$, and with slip magnitude, $b$ :

$$
q_{C A T}=\frac{\int_{t=0}^{t=t_{C A T}} q(t) d t}{t_{C A T}}=\frac{\int_{t=0}^{t=t_{C A T}} \theta \frac{k \gamma G b}{\mu d \sqrt{c t}} d t}{t_{C A T}}=\frac{b}{d} \theta_{C A T} .
$$

Plugging the maximum observed downflow rate of $-0.7 \mathrm{~mm}$ $\mathrm{d}^{-1}\left(-8 \times 10^{-9} \mathrm{~m} \mathrm{~s}^{-1}\right)$ for $q_{\mathrm{CAT}}$, the maximum predicted downflow rate of $-2 \times 10^{-4} \mathrm{~m} \mathrm{~s}^{-1}$ for $\theta_{\mathrm{CAT}}$ (Figure 4), and the average fault depth required to produce peak downflow at site 2:

$$
d=\frac{x}{3.1}=\frac{6.3 \mathrm{~km}}{3.1}=2.0 \mathrm{~km}
$$

into equation (16), we determine a minimum slip magnitude of $8 \mathrm{~cm}$.

[33] Matching the observed flow rate amplitudes with slow slip model predictions requires much larger slip magnitudes than in the instantaneous slip model because a significant loss of pressure head occurs as fluids drain through the surface for the duration of the slow slip event. The slip magnitude required to generate observed flow rates at site 2 is estimated after scaling the best fit model prediction, $\theta_{p}\left(L_{f x} / d=6\right.$ and $\left.\chi_{p}=0.4 \mathrm{~m}\right)$, for sediment material properties (Table 1), fault parameters $L_{f x}=12.2 \mathrm{~km}$ and $d=2.1 \mathrm{~km}$, and propagation speed $V_{x}=0.47 \mathrm{~km} \mathrm{~d}^{-1}$ (section 3.3) using equation (11). The remaining parameter required in dimensionalization, the slip magnitude, adjusts the flow rate amplitude. We find a minimum misfit is obtained with $b_{f}=4.8 \mathrm{~m}$. Of the same order, the approximate best fit model for site 3 requires a $3.0 \mathrm{~m}$ slip magnitude (Figure 10a).

\subsection{Discussion}

[34] Slow slip rupture parameters derived independently to match observations at different along-strike distances require downdip propagation at site 2 and updip propagation at site $3,15 \mathrm{~km}$ NW along strike. For a single slow slip event to produce the observed flow rate time series at each of the sites, the initiation and extent of rupture must have varied in the along-strike direction. For example, the rupture may have initiated along a line subparallel to the trench axis that runs from updip of site 2 to downdip of site 3 . By propagating in both updip and downdip directions from this initiation line, observations at sites 2 and 3 could be simultaneously reproduced. Similar bidirectional propagation of slow slip events have been observed with onshore GPS networks, e.g., in Cascadia [Melbourne et al., 2005], and inferred from anomalous hydrologic measurements recorded at an offshore Costa Rica borehole [Davis and Villinger, 2006] after initiation of an onshore slip event in
2003 [Protti et al., 2004]. Future three-dimensional modeling efforts are necessary to rigorously test this hypothesis.

[35] Slip magnitudes required to reproduce observed flow rates are likely overestimates; in particular, they are similar to the $4.25 \mathrm{~m}$ slip suggested by Cutillo et al. [2006] for a great earthquake based on the plate convergence rate of 8.5 $\mathrm{cm} \mathrm{a}^{-1}$ and a 50-year recurrence interval. It is highly improbable that the slow slip events occur every 50 years, especially since three of these events are observed in the 6month observation period. Alternative explanations include (1) the assumed permeability is too low, (2) absolute flow rate measurements are biased toward high values, and (3) the rupture depth is overestimated. Any number of these factors combined could account for the overestimate of slip magnitude required to produce the observation.

[36] Measurements of seafloor sediment permeability are done on push core samples in the laboratory. The upper few centimeters of sample are likely disturbed during sample collection and transportation. The measured permeability of the remaining core sample may not accurately represent that of the very near surface sediments to which the model predictions of flow rate amplitude are most sensitive. In addition, modeled permeability could also be undervalued if there is a dynamic effect of movement of overpressured and underpressured pore fluids in the near-surface sediment creating new pathways during the time of the fault slip event. Either way, if the marine sediment were more permeable than modeled, a smaller slip magnitude would be required to produce the observed flow rates. Simplifying equations (11) and (2) gives

$$
q \propto b_{f} \sqrt{k}=\frac{b_{f}}{10} \sqrt{100 k}
$$

A 2 orders of magnitude increase in permeability would reduce the required slip magnitude ten fold.

[37] Regarding the possibility of a bias in the measured flow rates, background rates measured at sites 2 and 5 are almost $10 \mathrm{~cm} \mathrm{a}^{-1}$, on the order of magnitude expected at seep sites, not at ambient seafloor sites. While CAT meter relative flow rate determinations are very reliable, one might question the accuracy of absolute flow rate determinations. In special circumstances daily tidal oscillations may dilute the tracer concentration of fluid samples used for flow rate determination and result in amplification of absolute flow rate measurements (M. D. Tryon, personal communication, 2007).

[38] Rupture on a shallower fault than the modeled decollement would require a proportionately lower slip to produce the same surface flow rate:

$$
q \propto \frac{b_{f}}{d}
$$

The deformation zone between the trench and the Nicoya basement complex backstop, $\sim 5-7 \mathrm{~km}$ distant from the trench and below observation sites 2, 3, and 5, is heavily populated with out-of-sequence thrust faults cutting from the decollement through to the surface (Figure 8) [Shipley et al., 1992; Silver, 2001]. A smaller amount of slip on a shallow out-of-sequence thrust fault could potentially 

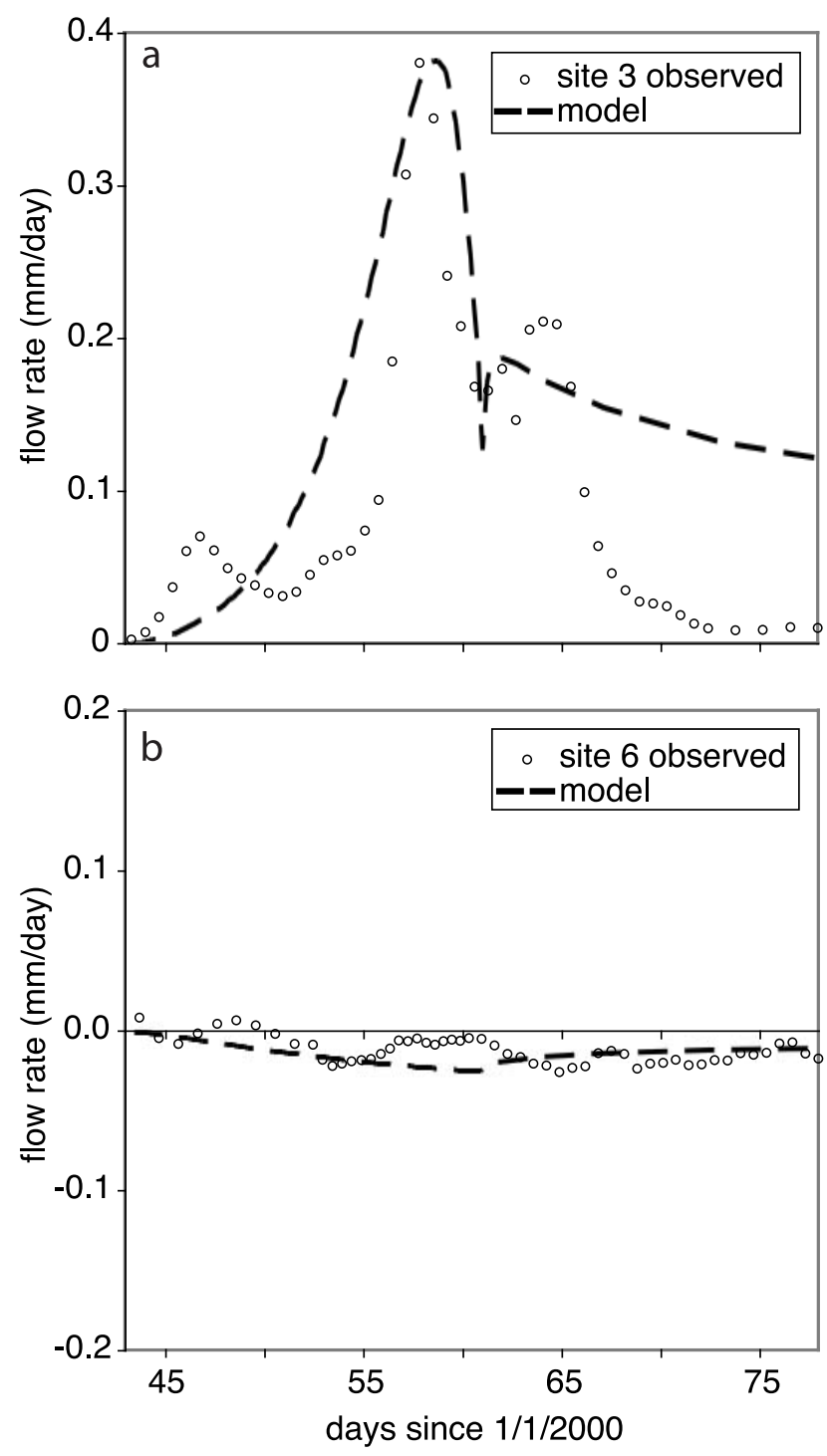

Figure 10. Updip propagating slow $\operatorname{slip}\left(L_{f x}=7.5 \mathrm{~km}, d=\right.$ $\left.3 \mathrm{~km}, V_{x}=-0.42 \mathrm{~km} \mathrm{~d}^{-1}, b_{f}=3.0 \mathrm{~m}\right)$ predictions for observations (background flow rates removed) at (a) site 3 , $6.8 \mathrm{~km}$ from trench $\left(\chi_{p}=1.1\right)$, and (b) site $6,26 \mathrm{~km}$ from trench $\left(\chi_{p}=-1.5\right)$.

reproduce the observed flow rate time series although it is improbable that such a shallow and narrow rupture would extend the $15 \mathrm{~km}$ along-strike distance between sites 2 and 3. Advances in processing techniques of very low frequency (VLF) earthquake and tremor signals [Ito and Obara, 2006; Ito et al., 2007] recorded on ocean bottom seismometers may provide a constraint on the average depth of slow slip propagation in future studies.

[39] It is conceivable that a rupture with a skewed slip distribution and change in propagation rate, which may occur if the rupture passes through a change in material or stress properties, could generate the observed flow rate time series. In the absence of GPS monitoring capability at offshore subduction zones, future studies that capture a second flow rate time series observation from above the slow slip event at the same along-strike location would allow for investigation of alternative slip histories. Despite these alternatives the distinctive flow rate patterns generated by updip and downdip propagating ruptures allow for (1) a first-order approximation of the location of a slip event producing the hydrologic anomaly, (2) a characterization of the event as an instantaneous or propagating slow slip rupture, and (3) if the event is slowly slipping, determination the propagation direction as updip or downdip.

\section{Conclusions}

[40] Finite element simulations of strain induced during slow slip events demonstrate that spatial and temporal records of seafloor pore pressure and fluid flux can be used to detect and quantify the rupture parameters. Hydrologic observations at the seafloor are particularly well suited for constraining the location and timing of offshore events during the interseismic period. In a case study, we constrained the characteristics of an offshore slow slip event through forward modeling to reproduce two seafloor flow rate time series recorded on the Costa Rica prism toe in 2000. Without additional observations, assumptions of the most probable fault plane location and slip history had to be made. The best fit model requires that the rupture initiated within the prism toe, i.e., at depth of less than $4 \mathrm{~km}$, and propagated at $0.5 \mathrm{~km} \mathrm{~d}^{-1}$ over a period of approximately 3 weeks. The absence of anomalous flow signals at sites further landward supports the conclusion that the slow slip event initiated in the shallow part of the subduction zone without any triggering from a nearby seismic or aseismic event such as in the seismogenic zone further downdip. Like the hypothesized 2003 slow slip event on the shallow decollement off Nankai's Cape Muroto that produced pressure anomalies and caused VLF events [Davis et al., 2006] and a similar event off the nearby Kii Peninsula in 2004 [Obara and Ito, 2005, Davis et al., 2009], this Costa Rica slow slip event cannot be explained using a simple subduction fault model with zones that are strictly stable sliding or stick slip. Instead, the inferred transient slow slip event during the interseismic period suggests complex dynamic behavior in the frontal prism.

[41] The initiation of the shallow slip event appears to be independent of any triggering event further downdip. This raises questions of the mechanism and timing of stress accumulation in the shallow section. Was the event a delayed release of stress in the updip section left over from movement of the seismogenic zone during the last great earthquake? Or, with locking at the seismogenic zone, does this event represent shortening or flexing in the incoming plate with respect to the overlying prism? It is also possible that the downdip "seismogenic" zone may have slipped aseismically, at a depth too great for our instruments to detect, and triggered slip in the frontal prism. Regardless of the cause for episodic slow slip in the shallow subduction zone, quantification of these events is important for future efforts to assess the tsunamogenic potential of the next Costa Rica subduction zone earthquake in the vicinity of the Nicoya Peninsula.

[42] New hydrologic instruments in development will assist in this effort to constrain interseismic transient slip. Flowmeters that can detect ultraslow flow rates, like the 
CAT meter, but have a high-temporal resolution and accuracy, like the electronic flowmeter [LaBonte et al., 2007], will allow for precise comparison of the timing of transient events recorded on different instruments. Piezometer probes and borehole hydrologic observatories for directly measuring pore pressures in the near seafloor sediment may allow for more accurate slip magnitude estimates as they are not subject to potential errors in permeability estimates or absolute flow rate determinations. With future long-term records from these surface instruments, and the forward modeling approach for quantitatively interpreting hydrologic data as presented in this study, significant progress can be made to characterize strain accumulation and release in offshore subduction zone environments during the earthquake cycle's interseismic stage.

[43] Acknowledgments. We would like to thank colleagues Earl Davis and Kelin Wang at the Pacific Geoscience Centre and reviewers Timothy Masterlark and Susan Ellis for their valuable critiques of this manuscript. Neil Driscoll and Vistasp Karbhari also deserve gratitude for use of computer facilities and an Abaqus license, respectively. Thanks to Leroy Dorman and Michael Tryon for engaging in scientific and technical discussions and collecting the field data. The National Science Foundation (OCE02-41998) and the Achievement Rewards for College Scientists Foundation, San Diego Chapter, have generously provided funding for the bulk of this work, and Alison LaBonte is grateful for her postdoctoral funding from University of Victoria's NEPTUNE program.

\section{References}

Becker, K., and E. E. Davis (2004), In situ determinations of the permeability of the igneous oceanic crust, in Hydrogeology of the Oceanic Lithosphere, edited by E. E. Davis and H. Elderfield, pp. 189-224, Cambridge Univ. Press, Cambridge, U. K.

Biot, M. A. (1941), General theory of three-dimensional consolidation, J. Appl. Phys., 12, 155-164, doi:10.1063/1.1712886.

Bolton, A. J., P. Vannucchi, M. B. Clennell, and A. Maltman (2001), Microstructural and geomechanical constraints on fluid flow at the Costa Rica convergent margin, Ocean Drilling Program Leg 170, Proc. Ocean Drill. Program Sci. Results, 170, 32 pp.

Brown, K. M., M. D. Tryon, H. R. DeShon, L. M. Dorman, and S. Y. Schwartz (2005), Correlated transient fluid pulsing and seismic tremor in the Costa Rica subduction zone, Earth Planet. Sci. Lett., 238, 189203, doi:10.1016/j.epsl.2005.06.055.

Carslaw, H. S., and J. C. Jaeger (1959), Conduction of Heat in Solids, 510 pp., Oxford Univ. Press, New York.

Christeson, G. L., K. D. McIntosh, T. H. Shipley, E. R. Flueh, and H. Goedde (1999), Structure of the Costa Rica convergent margin, offshore Nicoya Peninsula, J. Geophys. Res., 104, 25,443-25,468, doi:10.1029/1999JB900251

Cutillo, P. A., S. Ge, and E. Screaton (2006), Hydrodynamic response of subduction zones to seismic activity: A case study for the Costa Rica Margin, Tectonophysics, 426, 167-187, doi:10.1016/j.tecto.2006.02.017.

Davis, E. E., and H. W. Villinger (2006), Transient formation fluid pressures and temperatures in the Costa Rica forearc prism and subducting oceanic basement: CORK monitoring at ODP sites 1253 and 1255, Earth Planet. Sci. Lett., 245, 232-244, doi:10.1016/j.eps1.2006.02.042.

Davis, E. E., K. Wang, K. Becker, and R. E. Thomson (2000), Formationscale hydraulic and mechanical properties of oceanic crust inferred from pore pressure response to periodic seafloor loading, J. Geophys. Res., 105, 13,423-13,435, doi:10.1029/2000JB900084.

Davis, E. E., K. Becker, K. Wang, K. Obara, Y. Ito, and M. Kinoshita (2006), A discrete episode of seismic and aseismic deformation of the Nankai trough subduction zone accretionary prism and incoming Philippine Sea plate, Earth Planet. Sci. Lett., 242, 73-84, doi:10.1016/ j.eps1.2005.11.054

Davis, E. E., K. Becker, K. Wang, and M. Kinoshita (2009), Co-seismic and post-seismic pore-fluid pressure changes in the Philippine Sea plate and Nankai decollement in response to a seismogenic strain event off Kii Peninsula, Japan, Earth Planets Space, in press.

Dragert, H., K. L. Wang, and T. S. James (2001), A silent slip event on the deeper Cascadia subduction interface, Science, 292, 1525-1528, doi:10.1126/science.1060152.

Dragert, H., K. Wang, and G. Rogers (2004), Geodetic and seismic signatures of episodic tremor and slip in the northern Cascadia subduction zone, Earth Planets Space, 56, 1143-1150.
Fialko, Y. (2004a), Evidence of fluid-filled upper crust from observations of postseismic deformation due to the $1992 \mathrm{M}_{\mathrm{w}} 7.3$ Landers earthquake, J. Geophys. Res., 109, B08401, doi:10.1029/2004JB002985.

Fialko, Y. (2004b), Temperature fields generated by the elastodynamic propagation of shear cracks in the Earth, J. Geophys. Res., 109, B01303, doi:10.1029/2003JB002497.

Fialko, Y. (2007), Fracture and Frictional Mechanics-Theory, in Treatise on Geophysics, vol. 4, edited by G. Schubert, pp. 83-106, Elsevier, Oxford, U. K.

Hasegawa, A., N. Uchida, T. Igarashi, T. Matsuzawa, T. Okada, S. Miura, and Y. Suwa (2007), Asperities and quasi-static slips on the subducting plate boundary east of Tohoku, northeast Japan, in The Seismogenic Zone of Subduction Thrust Faults, edited by T. Dixon and J. C. Moore, pp. 451-475, Columbia Univ. Press, New York.

Ito, Y., and K. Obara (2006), Dynamic deformation of the accretionary prism excites very low frequency earthquakes, Geophys. Res. Lett., 33 , L02311, doi: $10.1029 / 2005 \mathrm{GL} 025270$.

Ito, Y., K. Obara, K. Shiomi, S. Sekine, and H. Hirose (2007), Slow earthquakes coincident with episodic tremors and slow slip events, Science, 315, 503-506, doi:10.1126/science. 1134454 .

Jacobson, R. S., L. M. Dorman, G. M. Purdy, A. Schultz, and S. C. Solomon (1991), Ocean bottom seismometer facilities available, Eos Trans. AGU, 72, 506, doi:10.1029/90EO00366.

Jonsson, S., P. Segall, R. Pedersen, and G. Bjornsson (2003), Postearthquake ground movements correlated to pore-pressure transients, Nature, 424, 179-183, doi:10.1038/nature01776.

Kimura, G., E. Silver, and P. Blum (1997), Proceedings of the Ocean Drilling Program, Initial Reports, vol. 170, 458 pp., Ocean Drill. Program, College Station, Tex.

LaBonte, A. L. (2007), An investigation of deformation and fluid flow at subduction zones using newly developed instrumentation and finite element modeling, Ph.D. thesis, 226 pp., Univ. of Calif., San Diego, La Jolla.

LaBonte, A. L., K. M. Brown, and M. D. Tryon (2007), Monitoring periodic and episodic flow events at Monterey Bay seeps using a new optical flow meter, J. Geophys. Res., 112, B02105, doi:10.1029/2006JB004410.

Lawn, B. (1993), Fracture of Brittle Solids, 378 pp., Cambridge Univ. Press, New York.

Masterlark, T. (2003), Finite element model predictions of static deformation from dislocation sources in a subduction zone: Sensitivities to homogeneous, isotropic, Poisson-solid, and half-space assumptions, J. Geophys. Res., 108(B11), 2540, doi:10.1029/2002JB002296.

Melbourne, T. I., W. M. Szeliga, M. M. Miller, and V. M. Santillan (2005), Extent and duration of the 2003 Cascadia slow earthquake, Geophys. Res. Lett., 32, L04301, doi:10.1029/2004GL021790.

Nishimura, T., et al. (2000), Distribution of seismic coupling on the subducting plate boundary in northeastern Japan inferred from GPS observations, Tectonophysics, 323, 217-238, doi:10.1016/S0040-1951(00) 00108-6.

Norabuena, E., et al. (2004), Geodetic and seismic constraints on some seismogenic zone processes in Costa Rica, J. Geophys. Res., 109, B11403, doi:10.1029/2003JB002931.

Obara, K. (2002), Nonvolcanic deep tremor associated with subduction in southwest Japan, Science, 296, 1679-1681, doi:10.1126/science. 1070378 .

Obara, K., and Y. Ito (2005), Very low frequency earthquakes excited by the 2004 off the Kii peninsula earthquakes: A dynamic deformation process in the large accretionary prism, Earth Planets Space, 57, 321-326.

Protti, M. V. Gonzalez, T. Kato, T. Iinuma, S. Miyazaki, K. Obana, Y. Kaneda, P. La Femina, T. Dixon, and S. Y. Schwartz (2004), A creep event on the shallow interface of the Nicoya Peninsula, Costa Rica seismogenic zone, Eos Trans. AGU, 85(47), Fall Meet. Suppl., Abstract S41D-07.

Rice, J. R., and M. P. Cleary (1976), Some basic stress diffusion solutions for fluid-saturated elastic porous-media with compressible constituents, Rev. Geophys., 14, 227-241, doi:10.1029/RG014i002p00227.

Roeloffs, E. (1996), Poroelastic techniques in the study of earthquakerelated hydrologic phenomena, Adv. Geophys., 37, 135-195.

Roeloffs, E., and J. W. Rudnicki (1985), Coupled deformation-diffusion effects on water-level changes due to propagating creep events, Pure Appl. Geophys., 122, 560-582, doi:10.1007/BF00874617.

Rogers, G., and H. Dragert (2003), Episodic tremor and slip on the Cascadia subduction zone: The chatter of silent slip, Science, 300, 1942-1943, doi:10.1126/science.1084783.

Rudnicki, J. W. (1986), Slip on an impermeable fault in a fluid-saturated rock mass, in Earthquake Source Mechanics, Geophys. Monogr. Ser, vol. 37, edited by S. Das, J. Boatwright, and C. H. Scholz, pp. 81-89, AGU, Washington, D. C

Rudnicki, J. W. (1987), Plane-strain dislocations in linear elastic diffusive solids, J. Appl. Mech., 54, 545-552. 
Schwartz, S. Y., and H. R. DeShon (2007), Distinct up-dip limits to geodetic locking and microseismicity at the northern Costa Rica seismogenic zone: Evidence for two mechanical transitions, in The Seismogenic Zone of Subduction Thrust Faults, edited by T. Dixon and J. C. Moore, pp. 576-599, Columbia Univ. Press, New York.

Screaton, E. J., and S. Ge (2007), Modeling of the effects of propagating thrust slip on pore pressures and implications for monitoring, Earth Planet. Sci. Lett., 258, 454-464, doi:10.1016/j.epsl.2007.04.004.

Shipley, T. H., K. D. McIntosh, E. A. Silver, and P. L. Stoffa (1992), 3-dimensional seismic imaging of the Costa Rica Accretionary Prism: Structural diversity in a small volume of the lower slope, J. Geophys. Res., 97, 4439-4459, doi:10.1029/91JB02999.

Silver, E. A. (2001), Leg 170: Synthesis of fluid-structural relationships of the Pacific margin of Costa Rica, Proc. Ocean Drill. Program Sci. Results, 170, 11 pp.

Spinelli, G. A., E. R. Giambalvo, and A. T. Fisher (2004), Sediment permeability, distribution, and influence on fluxes in oceanic basement, in Hydrogeology of the Oceanic Lithosphere, edited by E. E. Davis and H. Elderfield, pp. 151-188, Cambridge Univ. Press, Cambridge, U. K.

Tryon, M. D. (2002), The development and application of a new benthic aqueous flux meter for very low to moderate discharge rates, Ph.D. thesis, 135 pp., Univ. of Calif., San Diego, La Jolla.

Tryon, M. D. (2009), Monitoring aseismic tectonic processes via hydrologic responses: An analysis of log-periodic fluid flow events at the Costa Rica outer rise, Geology, 37, 163-166.
Tryon, M. D., and K. M. Brown (2000), Results from long-term aqueous flux measurements on the Costa Rican convergent margin, Eos Trans. $A G U, 81(48), 1161$.

Tryon, M., K. Brown, L. R. Dorman, and A. Sauter (2001), A new benthic aqueous flux meter for very low to moderate discharge rates, Deep Sea Res., Part I, 48, 2121-2146, doi:10.1016/S0967-0637(01)00002-4.

Turcotte, D. L., and G. Schubert (2002), Geodynamics, 456 pp., Cambridge Univ. Press, Cambridge, U. K.

Wang, H. F. (2000), Theory of Linear Poroelasticity With Applications to Geomechanics and Hydrogeology, 287 pp., Princeton Univ. Press, Princeton, N. J.

Wang, K., and E. E. Davis (1996), Theory for the propagation of tidally induced pore pressure variations in layered subseafloor formations, J. Geophys. Res., 101, 11,483-11,495, doi:10.1029/96JB00641.

Wang, K., and J. He (2008), Effects of frictional behaviour and geometry of subduction fault on coseismic seafloor deformation, Bull. Seismol. Soc. Am., 98, 571-579, doi:10.1785/0120070097.

Wang, K., and Y. Hu (2006), Accretionary prisms in subduction earthquake cycles: The theory of dynamic Coulomb wedge, J. Geophys. Res., 111, B06410, doi:10.1029/2005JB004094.

K. M. Brown and Y. Fialko, Scripps Institution of Oceanography, 9500 Gilman Drive, La Jolla, CA 92093, USA.

A. L. LaBonte, NEPTUNE Canada, University of Victoria, P.O. Box 1700 STN CSC, Victoria, BC V8W 2Y2, Canada. (alabonte@uric.ca) 